\title{
Preparing Ca-P coating on biodegradable magnesium alloy by hydrothermal method: In vitro degradation behavior
}

\author{
LI KaiKai ${ }^{1,2}$, WANG Bing ${ }^{1,2}$, YAN Biao $^{1,2} \&$ LU Wei $^{1,2^{*}}$ \\ ${ }^{1}$ School of Material Science and Engineering, Tongji University, Shanghai 201804, China; \\ ${ }^{2}$ Shanghai Key Laboratory of D\&A for Metal-Functional Materials, Tongji University, Shanghai 201804, China
}

Received August 15, 2011; accepted October 27, 2011; published online April 24, 2012

\begin{abstract}
Magnesium alloys are potentially attractive biodegradable materials. However, their rapid corrosion rate limits their biomedical application. To slow down the rate of biodegradation, a protective calcium-phosphate coating was formed on a magnesium alloy substrate by a hydrothermal method. Scanning electron microscope results showed that the coating consisted of two layers with different crystalline characteristics. The loose outer layer showed a prism-like crystal structure, while the compact inner layer is a dense ultra-fine regular di-pyramid-like structure with an average grain dimension of $\sim 200 \mathrm{~nm}$. The compositions of the inner layer and outer layer were calcium-deficient hydroxyapatite (Ca-def HA) and dicalcium phosphate (DCPa), respectively. The coating adhered well to the substrate with a thickness of about $15 \mu \mathrm{m}$. Immersion in Hank's solution indicated that the coating could significantly improve the degradation properties of magnesium alloy. The $\mathrm{pH}$ of the solution containing the coated samples increased much more slowly than the untreated control. After $8 \mathrm{~d}$ immersion, the uncoated sample had corroded seriously while the coated sample was much less corroded. The $\mathrm{Ca} / \mathrm{P}$ atom ratio in both the layers of the coating increased and the coating was still protecting the substrate. The two layers of the coating corroded differently because of differences in solubility. The outer layer was more severely attacked and many holes were formed on the surface, the inner layer suffered less attack. In addition, a growth of precipitate on the inner layer was observed, indicating that surface bioactivity was improved by the coating. Thus, magnesium alloys coated with a Ca-P coating prepared by a hydrothermal method are promising candidate biodegradable biomaterials, and further investigation of in vivo degradation behavior is suggested.
\end{abstract}

biomaterials, magnesium alloys, Ca-P coating, hydrothermal method, degradation, hydroxyapatite

Citation: $\quad$ Li K K, Wang B, Yan B, et al. Preparing Ca-P coating on biodegradable magnesium alloy by hydrothermal method: In vitro degradation behavior. Chin Sci Bull, 2012, 57: 2319-2322, doi: 10.1007/s11434-012-5067-5

Metallic materials such as stainless steels and titanium alloys continue to play an essential role as biomaterials in orthopedic surgery. However, traditional biomedical implant materials increase the risk of local inflammation as a foreign body in human tissue. Previous studies have shown that magnesium alloys are potential biodegradable materials with suitable biological performances addressing the above problem [1]. The fracture toughness of magnesium alloys is higher than that of bioceramics and polymers, but lower than that of stainless steels and titanium alloys, whilst the elastic modulus is closer to that of natural bone than other

*Corresponding author (email: vinomver@ hotmail.com) implant materials [2]. Magnesium ions are both harmless to the human body and also important in physiological activities; it has been shown that the presence of magnesium ions can accelerate the growth of new bone tissue [3]. Unfortunately, the poor corrosion resistance properties of magnesium-based materials in vivo impede their clinical use. The degradation time of the magnesium implants cannot match the rate of healing or regeneration of damaged bone. Recently, several methods have been suggested to slow down the biodegradation rate of magnesium alloys, such as element alloying, ion implantation, mechanical treatment and surface coating. In addition to improving the corrosion resistance property of magnesium alloys, biocompatibility 
should also be considered. Putting a Ca-P coating onto a magnesium alloy could improve both properties. Ca-P coatings such as $\mathrm{HA}, \mathrm{DCPD}, \beta-\mathrm{Ca}_{2} \mathrm{P}_{2} \mathrm{O}_{7}$ and $\beta$-TCP, are close in composition to natural bone and can accelerate the bone growth [4-6]. Therefore, in this study, a Ca-P coating is prepared on a ZK60 magnesium alloy substrate, a material compatible with human tissue [7]. Methods reported to form a Ca-P coating on a magnesium alloys substrate include chemical conversion and electro deposition, but so far, little has been published on fabricating a Ca-P coating on $\mathrm{Mg}$ alloy by hydrothermal methods. The aim of this study is to form Ca-P coating on a ZK60 magnesium alloy surface by a hydrothermal method, and thence to improve the rate of biodegradation.

\section{Material and methods}

The substrate material is ZK60 magnesium alloy which was cut into rectangular specimens. Each sample was mechanically polished up to 2000 grit, cleaned in deionized water and ethanol, and then dried in open air. In preparation for Ca-P coating, the samples were first immersed in saturated $\mathrm{Ca}(\mathrm{OH})_{2}$ solution for $24 \mathrm{~h}$ at room temperature. The 0.05 $\mathrm{mol} / \mathrm{L} \mathrm{Ca}\left(\mathrm{NO}_{3}\right)_{4} \cdot 4 \mathrm{H}_{2} \mathrm{O}$ and $0.03 \mathrm{~mol} / \mathrm{L} \mathrm{NaH} \mathrm{PO}_{4} \cdot 2 \mathrm{H}_{2} \mathrm{O}$ solution was poured into a hydrothermal reaction vessel filling it to $80 \%$ of capacity. To prepare the anticorrosive Ca-P coating, the calcified ZK60 samples were placed in the vessel and heated in an electric oven at $180^{\circ} \mathrm{C}$ for $1.5 \mathrm{~h}$. The samples were removed from the solution and gently rinsed with deionized water, and dried at room temperature. The surface morphologies of the coating were observed by SEM. The chemical composition of the surface coating was determined by energy dispersive spectroscopy. The phase structure of the coating was investigated by XRD. To evaluate the degradation property in vitro of the sample, immersion tests were conducted in Hank's solution $(\mathrm{NaCl} 8.0 \mathrm{~g} / \mathrm{L}$, $\mathrm{CaCl}_{2} 0.14 \mathrm{~g} / \mathrm{L}, \mathrm{KCl} 0.4 \mathrm{~g} / \mathrm{L}, \mathrm{NaHCO}_{3} 0.35 \mathrm{~g} / \mathrm{L}$, Glucose $1.0 \mathrm{~g} / \mathrm{L}, \mathrm{MgCl}_{2} \cdot 6 \mathrm{H}_{2} \mathrm{O} 0.1 \mathrm{~g} / \mathrm{L}, \mathrm{Na}_{2} \mathrm{HPO}_{4} \cdot 2 \mathrm{H}_{2} \mathrm{O} 0.06 \mathrm{~g} / \mathrm{L}$, $\left.\mathrm{KH}_{2} \mathrm{PO}_{4} 0.06 \mathrm{~g} / \mathrm{L}, \mathrm{MgSO}_{4} \cdot 7 \mathrm{H}_{2} \mathrm{O} 0.06 \mathrm{~g} / \mathrm{L}\right)$ at $310 \pm 0.5 \mathrm{~K}$.

\section{Results and discussion}

Figure 1 shows SEM images of the coating surface morphologies. The coating surface shows different crystalline characteristics. The outer layer has a prism-like crystal structure about 20-30 $\mu \mathrm{m}$ in size, as shown in Figure 1(a). The inner layer appears to be a dense ultra-fine regular dipyramid-like structure as shown in Figure 1(b), with a crystal dimension of $\sim 200 \mathrm{~nm}$. It is known that DCPa crystallizes as a triclinic form and hydroxyapatite forms a hexagonal
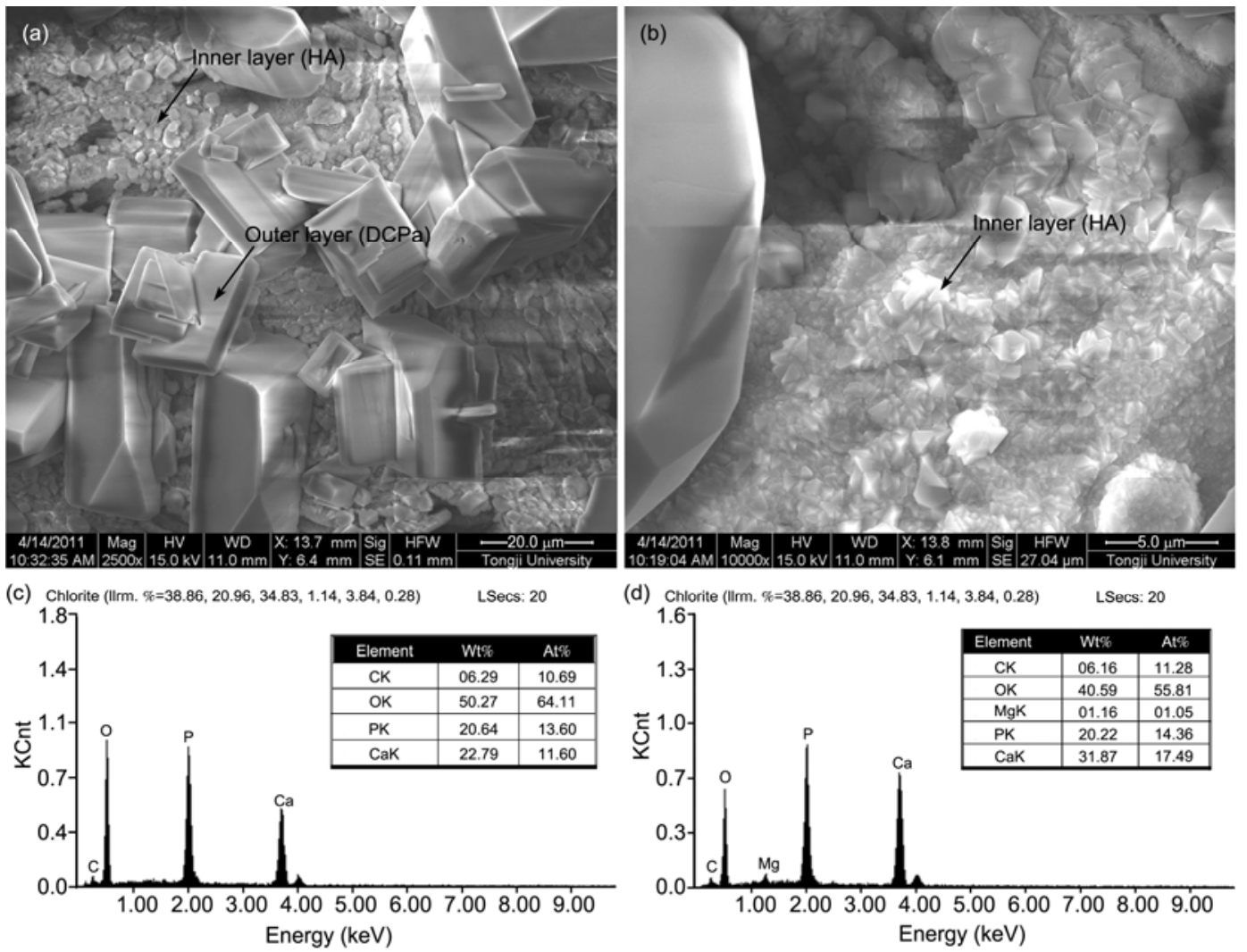

Figure 1 (a), (b) SEM morphologies of the coating; (c) EDS of the outer layer; (d) the inner layer. 
system, so these SEM morphologies indicate that the two layers are DCPa and HA. The outer layer crystals are uniformly embedded in the inner coating layer. No cracks are observed in the surface coating because of thermal or other stresses. EDS shows that the outer layer mainly consists of calcium, phosphorus, oxygen, and a small amount of carbon, and the $\mathrm{Ca} / \mathrm{P}$ molar ratio is about 0.85 , whilst the composition of the inner layer mainly consists of calcium, phosphorus, oxygen, and a small amount of magnesium and carbon elements, with a $\mathrm{Ca} / \mathrm{P}$ molar ratio of approximately 1.22 . The XRD results in Figure 2 indicate that the coating is composed of well crystallized dicalcium phosphate (DCPa) and Ca-deficient hydroxyapatite (Ca-Def HA), which is consistent with the SEM-EDS results. The fact that the $\mathrm{Ca} / \mathrm{P}$ molar ratio of the outer layer is lower than the theoretical value of DCPa may be due to the co-operation of $\mathrm{CO}_{3}^{2-}$. It has been reported that highly crystalline structures make less soluble coatings [8]. So the high crystallinity of the coating may decrease the biodegradation rate. In addition, the crisscross structure of the loose outer layer is highly microporous which is beneficial for the infiltration of bone tissue into the implants and will thus accelerate healing of the damaged bone [9].

The degradation behavior in vitro was investigated by immersion in $37^{\circ} \mathrm{C}$ Hank's solution. It can be seen that the
$\mathrm{pH}$ of the solution containing the coated samples increases more slowly than that of the untreated sample in the first $24 \mathrm{~h}$, as shown in Figure 3. It is known that this type of Hank's solution $\mathrm{pH}$ increase mainly results from the dissolution of $\mathrm{Mg}$ and the formation of the corrosion product $\mathrm{Mg}(\mathrm{OH})_{2}$, so it can be concluded that the corrosion rate of the coated samples is lower than that of the untreated samples. The $\mathrm{pH}$ of the solution with coated ZK60 falls below 8.1 during the immersion test, whilst the $\mathrm{pH}$ of the solution containing the untreated $\mathrm{Mg}$ quickly rises to 8.5. High $\mathrm{pH}$ physiological conditions are not compatible with cell growth. During the subsequent $4 \mathrm{~d}$ immersion, the $\mathrm{pH}$ of both the solutions decreases, which can be attributed to the formation of bone-like apatite that consumes the $\mathrm{OH}^{-}$in the Hank's solution [5]. The untreated ZK60 alloy suffers serious attack because of the presence of $\mathrm{Cl}^{-}$in Hank's solution, as shown in Figure 4(a). Significant white corrosion products are formed on the surface and many cracks can also be observed. The coated sample also suffers attack but the substrate is still undamaged, as shown in Figure 4(b). Most of the outer layer disappears and some holes can be seen on the surface, which may be due to the dissolution of DCPa. The inner layer remains integrated because of the low solubility of HA. The corrosion does not penetrate the coating which thus continues to protect the substrate from corrosion.

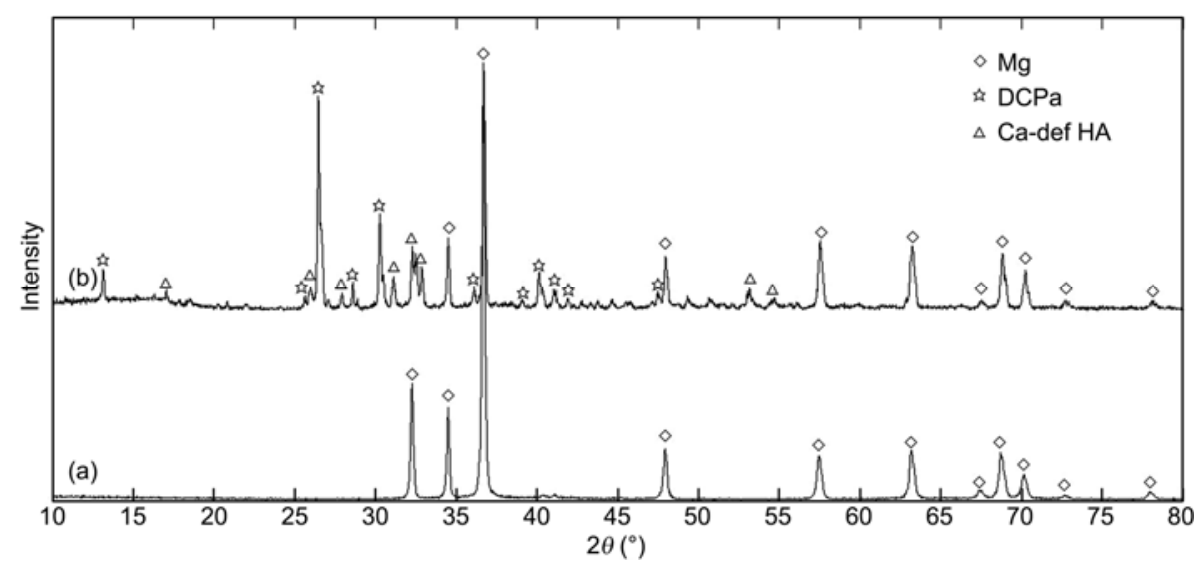

Figure 2 XRD patterns of ZK60 alloys. (a) Without coating; (b) with coating.

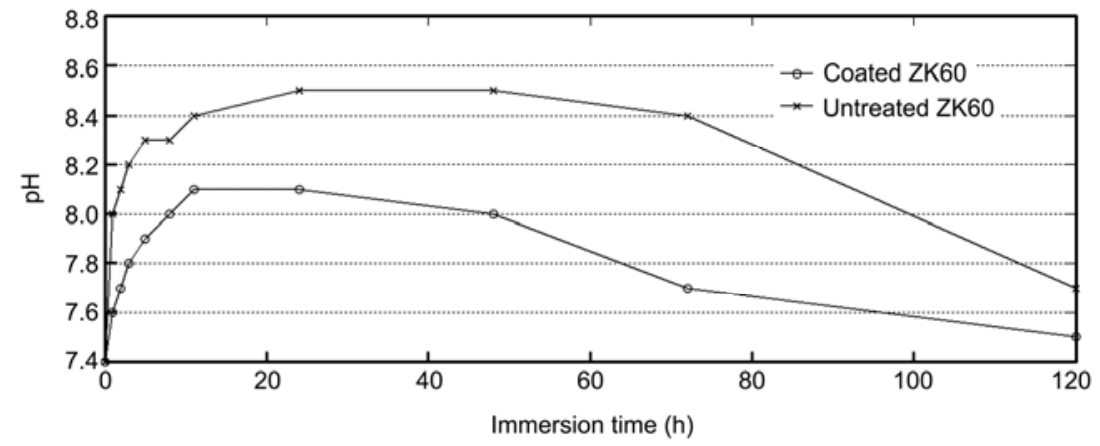

Figure 3 Change in $\mathrm{pH}$ of the Hank's solution with immersion time. 

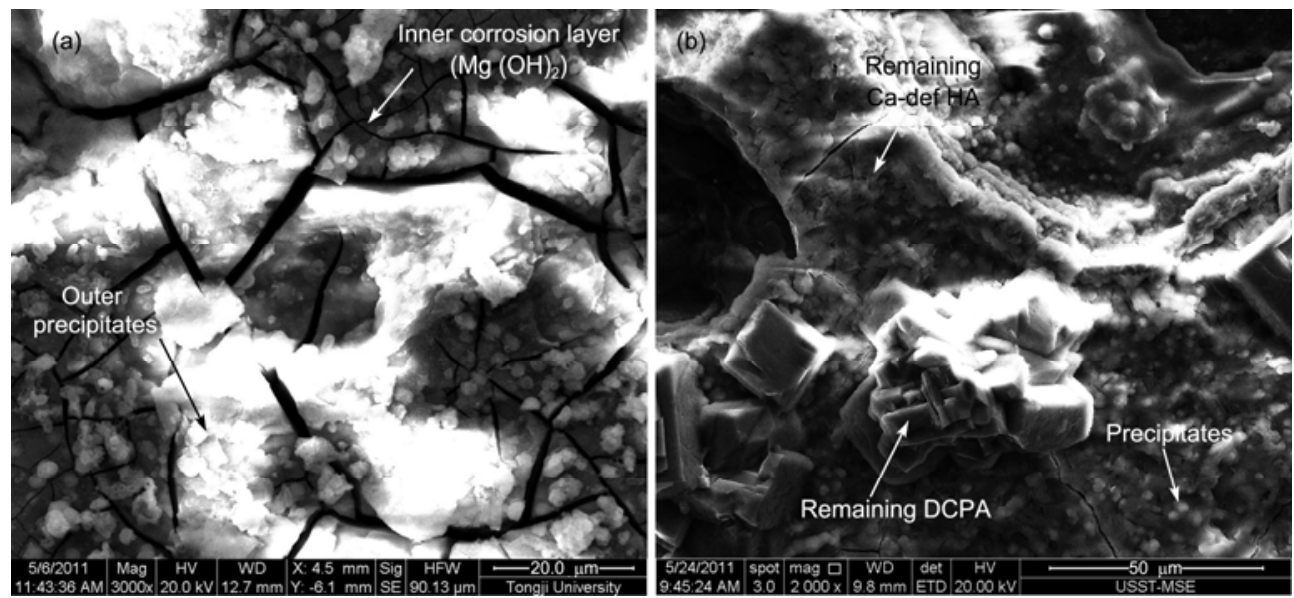

Figure 4 Corrosion morphologies of untreated (a) and coated (b) samples after $8 \mathrm{~d}$ immersion.

Spherulitic precipitates can be seen on the surface of the inner layer. At higher magnification, precipitates on the inner layer show in-situ growth with newly formed grains growing from the original inner grains. This leads to the formation of an interconnected porous structure, which is similar to the morphology of human bone [10]. This precipitation is beneficial to the bioactivity of the implants. The improvement in corrosion resistance greatly reduces the initial biodegradation rate of the implants, and is essential for maintaining the implant's mechanical strength during bone re-growth.

\section{Conclusion}

In summary, a bioactive Ca-P coating was successfully formed on a ZK60 magnesium alloy substrate by hydrothermal processing. The coating improves corrosion resistance in Hank's solution. The coating consists of two layers with different crystalline characteristics. The inner layer is composed of Ca-def hydroxyapatite (HA), while the outer layer is dicalcium phosphate (DCPa). The immersion test results indicate that the Ca-P coating significantly improve the biodegradation rate of magnesium alloys in Hank's solution. Thus, magnesium alloys coated with Ca-P coating prepared by hydro-thermal processing show promise as candidate materials for biodegradable orthopedic implants.
This work was supported by the Program for Young Excellent Talents in Tongji University (2009KJ003) and "Chen Guang" Project (10CG21) from the Shanghai Municipal Education Commission and Shanghai Education Development Foundation.

1 Witte F. The history of biodegradable magnesium implants. Acta Biomater, 2010, 6: 1680-1692

2 Staiger M P, Pietak A M, Huadmai J, et al. Magnesium and its alloys as orthopaedic biomaterials: A review. Biomaterials, 2006, 27: 1728-1734

3 Witte F, Kaese V, Haferkamp H, et al. In vivo corrosion of four magnesium alloys and the associated bone response. Biomaterials, 2005, 26: 3557-3563

4 Wen C L, Guan S K, Peng L, et al. Characterization and degradation behavior of AZ31 alloy surface modified by bone-like hydroxyapatite for implant applications. Appl Surf Sci, 2009, 255: 6433-6438

5 Geng F, Tan L L, Jin X X, et al. The preparation, cytocompatibility, and in vitro biodegradation study of pure beta-TCP on magnesium. J Mater Sci: Mater Med, 2009, 20: 1149-1157

6 Lin F H, Lin C C, Lu C M, et al. Mechanical-properties and histologicalevaluation of sintered beta- $\mathrm{Ca}_{2} \mathrm{P}_{2} \mathrm{O}_{7}$ with $\mathrm{Na}_{4} \mathrm{P}_{2} \mathrm{O}_{7} \cdot 10 \mathrm{H}_{2} \mathrm{O}$ addition. Biomaterials, 1995, 16: 793-802

7 He Y H, Tao H R, Zhang Y, et al. Biocompatibility of bio-Mg-Zn alloy within bone with heart, liver, kidney and spleen. Chin Sci Bull, 2009, 54: 484-491

8 Elia N, Sridhar T M, Kamachi M U, et al. Electrochemical and electrophoretic deposition of hydroxyapatite for orthopaedic application. Surf Eng, 2005, 21: 238-242

9 Park J H, Lee Y K, Kim K M. Bioactive calcium phosphate coating prepared on $\mathrm{H}_{2} \mathrm{O}_{2}$-treated titanium substrate by electrodeposition. Surf Coat Technol, 2005, 195: 252-257

10 Gibson L, Ashby M. Cellular solids. Structure and Properties. Sydney: Pergamon Press, 1988. 316-331

Open Access This article is distributed under the terms of the Creative Commons Attribution License which permits any use, distribution, and reproduction in any medium, provided the original author(s) and source are credited. 